\section{Commentary: Preaching to the wire}

\author{
Hellmuth R. Muller Moran, MD, ${ }^{\mathrm{a}, \mathrm{b}}$ and \\ Michael H. Yamashita, MDCM, MPH, FRCSC ${ }^{\mathrm{a}, \mathrm{b}}$
}

Mangukia and colleagues ${ }^{1}$ present an interesting case of pulmonary thromboendarterectomy complicated by arterial injury resulting in massive hemoptysis. Although the complication itself is not terribly novel-hemorrhage and hemoptysis are well-established risks of pulmonary thromboendarteretomy ${ }^{2,3}$ and the authors themselves admit that this is not the first occurrence at their institution-the method of treatment should be insightful for surgeons and trainees wishing to remain at the forefront of our specialty.

Cardiac surgery has generally been a specialty characterized by open surgical procedures. However, just as the advent of percutaneous coronary intervention revolutionized the treatment of ischemic heart disease, transcatheter procedures continue to change the care of other cardiovascular diseases that have traditionally been the domain of open surgery. Interventions for the aorta and aortic valve are already commonplace and, as this case demonstrates, transcatheter procedures can often improve on the perioperative risks of traditional open surgery. Although surgical intervention in the form of lobectomy was considered here, it was ultimately deemed a suboptimal option.

To offer the best care to their patients, it is imperative that cardiac surgeons develop at least a working knowledge of available wire-based techniques. The current climate of increased specialization may not realistically allow all cardiac surgeons to be as well-versed or proficient in these techniques as an interventional radiologist, vascular surgeon, or interventional cardiologist may be. It therefore behooves the cardiac surgeon to maintain open lines of

From the a Division of Cardiac Surgery, Department of Surgery, Max Rady College of Medicine, University of Manitoba; and ${ }^{\mathrm{b}}$ Cardiac Sciences Program, St Boniface Hospital, Winnipeg, Manitoba, Canada.

Disclosures: The authors reported no conflicts of interest.

The Journal policy requires editors and reviewers to disclose conflicts of interest and to decline handling or reviewing manuscripts for which they may have a conflict of interest. The editors and reviewers of this article have no conflicts of interest.

Received for publication Sept 13, 2020; revisions received Sept 13, 2020; accepted for publication Sept 24, 2020; available ahead of print Sept 28, 2020.

Address for reprints: Michael H. Yamashita, MDCM, MPH, FRCSC, St Boniface Hospital, Y3519-409 Tache Ave, Winnipeg, Manitoba, Canada R2H 2A6 (E-mail: myamashita@sbgh.mb.ca)

JTCVS Techniques 2020;4:150-1

2666-2507

Copyright $(2020$ The Authors. Published by Elsevier Inc. on behalf of The American Association for Thoracic Surgery. This is an open access article under the CC BY-NCND license (http://creativecommons.org/licenses/by-nc-nd/4.0/).

https://doi.org/10.1016/j.xjtc.2020.09.030

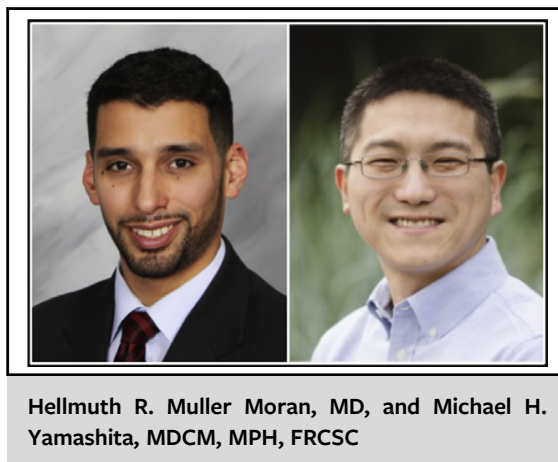

CENTRAL MESSAGE

In order to remain at the fore-

front of our specialty, cardiac

surgeons and trainees must

maintain at least a working

knowledge-and ideally a basic

skillset_in available wire-based

techniques.

communication with these complimentary specialties and to ideally establish a basic, fundamental skillset that can serve as a springboard for more advanced procedures.

It is clear that wire skills are an integral part of contemporary cardiac surgical practice and will continue to be for the foreseeable future. Indeed, most cardiac surgeons are already well aware of this fact, with many leaders in our field calling for greater emphasis to be placed on transcatheter skills during training. ${ }^{4,5}$ Emphasizing the importance of wire skills to cardiac surgeons is therefore very much like preaching to the choir. While the degree of surgical involvement in advanced procedures such as the described pulmonary artery coil embolization may vary by center and by surgeon, there are ample opportunities within our everyday activities to begin developing these skills. Trainees and acolytes take note; the wire is here to stay.

\section{References}

1. Mangukia C, Forfia P, Vaidya A, Williams V, Niman D, Rali P, et al. Percutaneous coil embolization to manage pulmonary artery hemorrhage after distal endarterectomy. J Thorac Cardiovasc Surg Tech. 2020;4:147-9.

2. Ansari A, Cobert J, Navuluri N, Cheng G, Haney JC, Welsby I. Intrapulmonary activated factor VII for hemoptysis complicating pulmonary thromboendarterectomy. Ann Thorac Surg. 2020;109:e243-5.

3. Rahnavardi M, Yan TD, Cao C, Vallely MP, Bannon PG, Wilson MK. Pulmonary thromboendarterectomy for chronic thromboembolic pulmonary hypertension: a systematic review. Ann Thorac Cardiovasc Surg. 2011;17:435-45. 
4. Nguyen TC, Tang GHL, Nguyen S, Forcillo J, George I, Kaneko T, et al. The train has left: can surgeons still get a ticket to treat structural heart disease? J Thorac Cardiovasc Surg. 2019;157:2369-76.e2.
5. Pelletier MP, Kaneko T, Peterson MD, Thourani VH. From sutures to wires: the evolving necessities of cardiac surgery training. J Thorac Cardiovasc Surg. 2017;154:990-3. 